05

\title{
Влияние зон Гинье-Престона на динамический предел текучести сплавов при ударно-волновом нагружении
}

\author{
(C) В.В. Малашенко
}

Донецкий фризико-технический институт им. А.А. Галкина, 83114 Донецк, Украина

e-mail: malashenko@fti.dn.ua

(Поступило в Редакцию 21 июня 2016 г.)

Теоретически исследовано движение ансамбля краевых дислокаций при ударно-волновом воздействии на сплав, содержащий зоны Гинье-Престона. Получено аналитическое выражение вклада зон Гинье-Престона в величину динамического предела текучести и показано, что этот вклад зависит от плотности подвижных дислокаций. Численные оценки показали, что образование этих зон приводит к существенному увеличению динамического предела текучести сплавов.

DOI: $10.21883 /$ JTF.2017.05.44458.1948

Техника ударных волн является мощным инструментом изучения материалов при экстремально высоких скоростях деформирования с хорошо контролируемыми условиями нагружения $[1,2]$. Импульсы ударной нагрузки создаются в образцах исследуемых материалов ударниками, разогнанными с помощью взрывных устройств, пневматических ствольных установок $[3,4]$, воздействием высокоинтенсивного лазерного или корпускулярного излучения [5], а также методом динамического канальноуглового прессования [6,7]. При этом скорость пластической деформации достигает значений $10^{3}-10^{7} \mathrm{~s}^{-1}$, а дислокации совершают надбарьерное скольжение и движутся со скоростями $v \geq 10^{-2}$ с, где $c-$ скорость распространения поперечных звуковых волн в кристалле. Это так называемая динамическая область, в которой дислокация преодолевает встречающиеся на ее пути препятствия без помощи термических флуктуаций.

Существенное влияние на движение дислокаций, а следовательно, и на механические свойства кристаллов, оказывает динамическое взаимодействие дислокаций с зонами Гинье-Престона, образующимися в сплавах в результате искусственного или естественного старения [8].

В работах $[8,9]$ методом молекулярной динамики анализировалось движение краевой дислокации в упругом поле зон Гинье-Престона. В настоящей работе показано, что возрастание плотности подвижных дислокаций при высокоскоростном деформировании приводит к возникновению эффекта сухого трения при их динамическом взаимодействии с зонами Гинье-Престона, в результате чего возрастает динамический предел текучести сплава.

Пусть бесконечные краевые дислокации совершают скольжение под действием постоянного внешнего напряжения $\sigma_{0}$ в положительном направлении оси $O X$ с постоянной скоростью $v$ в кристалле, содержащем хаотически распределенные зоны Гинье-Престона. Линии дислокаций параллельны оси $O Z$, их векторы Бюргерса $b=(b, 0,0)$ одинаковы и параллельны оси $O X$.
Плоскость скольжения дислокаций совпадает с плоскостью XOZ. Положение $k$-ой дислокации определяется функцией

$$
X_{k}(y=0, z, t)=v t+w_{k}(y=0, z, t) .
$$

Здесь $w_{k}(y=0, z, t)$ - случайная величина, описывающая изгибные колебания дислокации, возбужденные ее взаимодействием с хаотически распределенными дефектами. Среднее значение этой величины по длине дислокации и по хаотическому распределению дефектов равно нулю.

Зоны Гинье-Престона будем считать одинаковыми, имеющими радиус $R$, и распределенными случайным образом в плоскостях, параллельных плоскости скольжения дислокации XOZ. Такая ситуация реализуется, например, в сплавах $\mathrm{Al}-\mathrm{Cu}$, где зоны Гинье-Престона имеют форму пластинок моноатомной толщины [9].

Уравнение движения $k$-ой дислокации может быть представлено в следующем виде:

$$
m\left\{\frac{\partial^{2} X}{\partial t^{2}}-c^{2} \frac{\partial^{2} X}{\partial z^{2}}\right\}=b\left[\sigma_{0}+\sigma_{x y}^{G}\right]+F_{k}-B \frac{\partial X}{\partial t},
$$

где $\sigma_{x y}^{G}$ - компонента тензора напряжений, создаваемых на линии дислокации зонами Гинье-Престона, $F_{k}-$ сила, действующая на дислокацию со стороны остальных дислокаций ансамбля, $m$ - масса единицы длины дислокации (массы всех дислокаций считаем одинаковыми), $c$ - скорость распространения в кристалле поперечных звуковых волн, $B$ - константа демпфирования, обусловленная фононными, магнонными или электронными механизмами диссипации. Здесь, как и в работах [10-13], будем считать выполненным условие $\left[B b v /\left(m c^{2}\right)\right] \ll 1$, позволяющее пренебречь влиянием константы $B$ на силу торможения дислокации структурными дефектами.

Воспользовавшись методом, развитым в работах [10-13], силу динамического торможения (drag) 
движущейся краевой дислокации зонами Гинье-Престона вычислим по формуле

$$
F_{\mathrm{def}}=\frac{n_{G} b^{2}}{8 \pi^{2} m} \int d^{3} q\left|q_{x}\right| \cdot\left|\sigma_{x y}^{G}(q)\right|^{2} \delta\left(q_{x}^{2} v^{2}-\omega^{2}\left(q_{z}\right)\right),
$$

где $\omega\left(q_{z}\right)$ - спектр дислокационных колебаний, $\sigma_{x y}^{G}(q)$ - Фурье-образ компоненты тензора напряжений, созданных зонами Гинье-Престона, $n_{G}$ - объемная концентрация этих зон.

В рассматриваемом нами случае спектр дислокационных колебаний имеет вид

$$
\omega^{2}\left(q_{z}\right)=c^{2} q_{z}^{2}+\Delta^{2} .
$$

При ударно-волновом воздействии на кристалл плотность подвижных дислокаций значительно возрастает и может достигать значений $\rho=10^{15} \mathrm{~m}^{-2}$. Именно коллективное взаимодействие дислокаций в этом случае вносит главный вклад в формирование спектральной щели, величина которой, согласно [10], определяется формулой

$$
\Delta=\Delta_{\text {dis }}=\pi b \sqrt{\frac{\mu \rho}{6 \pi m(1-\gamma)}} \approx c \sqrt{\rho},
$$

где $\mu-$ модуль сдвига, $\gamma-$ коэффициент Пуассона. Выполняя вычисления, получим, что в интервале $v<v_{G}=R \Delta_{\text {dis }}$ сила динамического торможения дислокации зонами Гинье-Престона приобретает характер сухого трения и ее вклад в величину динамического предела текучести может быть описан выражением

$$
\tau_{G}=\frac{n_{G} \mu \eta^{2} b R}{(1-\gamma)^{2} \sqrt{\rho}}
$$

где $\eta$ - размерный фактор. Полученное выражение справедливо при скоростях движения дислокации $v<v_{G}$. Оценим величину характерной скорости $v_{G}$. Для значений $\rho=10^{15} \mathrm{~m}^{-2}, b=3 \cdot 10^{-10} \mathrm{~m}, c=3 \cdot 10^{3} \mathrm{~m} / \mathrm{s}$, $R=3 \cdot 10^{-9}$ m получим $v_{G}=10^{-1} \mathrm{c}$.

Выполним численную оценку вклада исследуемого механизма диссипации в величину динамического предела текучести. Для типичных значений $\mu=$ $=5 \cdot 10^{10} \mathrm{~Pa}, \eta=10^{-1}, b=3 \cdot 10^{-10} \mathrm{~m}, R=3 \cdot 10^{-9} \mathrm{~m}$, $n_{G}=4 \cdot 10^{24} \mathrm{~m}^{-3}, \quad \gamma=0.3$ получим $\tau_{G}=10^{8} \mathrm{~Pa}$, т.е. вклад динамического торможения зонами ГиньеПрестона может составлять десятки процентов.

Проведенный анализ показывает, что при ударноволновом нагружении сплавов зоны Гинье-Престона могут оказывать существенное влияние на процесс пластической деформации.

\section{Список литературы}

[1] Канель Г.И., Фортов В.Е., Разоренов С.В. // УФН. 2007. Т. 177. Вып. 8. С. 809-830.

[2] Lee J., Veysset D., Singer J., Retsch M., Saini G., Thomas E. // Nature Commun. 2012. N 3. P. 1164-1173.
[3] Жиляев П.А., Куксин А.Ю., Стегайлов В.В., Янилкин А.В. // ФТТ. 2010. Т. 52. Вып. 8. С. 1508-1512.

[4] Zaretsky E.B., Kanel G.I. // J. Appl. Phys. 2013. Vol. 114. P. 083511.

[5] Tramontina D., Bringa E., Erhart P., Hawreliak J., Germann T., Ravelo R., Higginbotham A., Suggit M., Wark J., Park N., Stukowski A., Tang Y. // High Energy Density Phys. 2014. Vol. 10. P. 9-15.

[6] Бородин И.Н., Майер А.Е. // ЖТФ. 2013. Т. 83, Т. 8. С. 7680.

[7] Зельдович В.И., Шорохов Е.В., Добаткин С.В., Фролова Н.Ю., Хейфеч А.Э., Хомская И.В., Насонов П.А., Ушаков А.A. // ФММ. 2011. Т. 111. № 2. С. 439-447.

[8] Singh C.V., Warner D.H. // Acta Material. Vol. 58. N 17. P. 5797-5805.

[9] Куксин А.Ю., Янилкин А.В. // МТТ. 2015. № 1. С. 54-65.

[10] Малашенко В.В. // ФТТ. 2014. Т. 56. Вып. 8. С. 1528-1530.

[11] Малашенко В.В. // ФТТ. 2015. Т. 57. Вып. 12. С. 2388-2390.

[12] Малашенко В.В. // Письма в ЖТФ. 2012. Т. 38. Вып. 19. C. 61-65.

[13] Malashenko V.V. // Phys. B: Phys. Cond. Mat. 2009. Vol. 404. 2. P. $3890-3892$. 